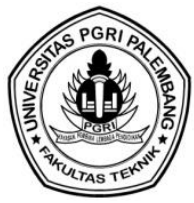

\title{
DESAIN MARKA JALAN DARI BETON DENGAN REPLACEMENT SYSTEM
}

\author{
Adiguna \\ Prodi Teknik Sipil Fakultas Teknik Universitas PGRI Palembang \\ Email : adigunaym@gmail.com
}

\begin{abstract}
ABSTRAK
Terjadinya benturan antara kendaraan mobil dan marka pengaman jalan dari beton mengakibatkan kendaraan menjadi rusak berak. Untuk itu perlu dilakukan penelitian khusus mengenai marka beton yang lebih aman bagi pengendara jalan manakala terjadi benturan. Desain marka beton yang aman bagi pengemudi dapat menggunakan bahan alternative diantaranya dengan memanfaatkan limbah bagus atau Styrofoam. Pengujian kuat tekan beton setelah berumur 28 hari diperoleh kuat tekan beton untuk beton normal sebesar $317,39 \mathrm{~kg} / \mathrm{cm}^{2}$, pada beton dengan penambahan Styrofoam $10 \%$ terjadi penurunan sebesar $258,96 \mathrm{~kg} / \mathrm{cm}^{2}$ dan penambahan Styrofoam $15 \%$ terjadi penurunan sebesar $222,49 \mathrm{~kg} / \mathrm{cm}^{2}$ dan pada penambahan Styrofoam $20 \%$ mengalami penurunan yang cukup siknifikan sebanyak $140,58 \mathrm{~kg} / \mathrm{cm}^{2}$. Maka disimpulkan bahwa beton yang dicampur Styrofoam mengalami penuruan signifikan dari desain awalnya. Ini menunjukkan bahwa marka beton yang didesain tersebut cukup mampu mengurangi beban benturan dari kendaraan. Selanjutnya marka beton yang telah rusak dapat diganti ulang atau replacement system.
\end{abstract}

Kata kunci : Marka, Beton, Styrofoam, Replacement System

\section{PENDAHULUAN}

Kecelakaan jalan raya yang sering terjadi terutama pada lintasan berkesepatan tinggi menelan banyak sekali korban. Terjadinya benturan antara kendaraan mobil dan marka pengaman jalan dari beton mengakibatkan kendaraan menjadi rusak berak. Untuk itu perlu dilakukan penelitian khusus mengenai marka beton yang lebih aman bagi pengendara jalan manakala terjadi benturan. Oleh sebab itu perlu didesain marka beton yang secara stuktural cukup kokoh terhadap beratnya sendiri dan pengaruh lingkungan, namun aman bagi pengendara jalan.

Desain marka beton yang aman bagi pengemudi dapat menggunakan bahan alternative diantaranya dengan memanfaatkan bahan additive baik kimia maupun berupa limbah dari kegiatan industri. Selanjutnya penelitian ini mencoba memanfaatkan limbah industri berupa limbah Styrofoam sebagai alternative bahan additive. Dengan asumsi bahwa beton yang dihasilkan dapat memenuhi desain seperti yang dimaksud di atas.

\section{TINJAUAN PUSTAKA}

Dalam konstruksi, beton adalah sebuah bahan bangunan (material) komposit yang terbuat dari kombinasi aggregat dan pengikat semen. Beton ini didapatkan dengan cara mencampur agregat halus (pasir), agregat kasar (kerikil), atau jenis agregat lain dan air, dengan semen portland atau semen hidrolik yang lain, kadang kadang dengan bahan tambahan (additif) yang bersifat kimiawi ataupun fisikal pada perbandingan tertentu, 
sampai menjadi satu kesatuan yang homogen. Campuran tersebut akan mengeras seperti batuan. Pengerasan terjadi karena peristiwa reaksi kimia antara semen dengan air.

Seiring dengan penambahan umur, beton akan semakin mengeras, dan akan mencapai kekuatan rencana ( f'c ) pada usia 28 hari. Kecepatan bertambahnya kekuatan beton ini sangat dipengaruhi oleh faktor air semen dan suhu selama perawatan. Kekuatan tekan merupakan salah satu kinerja utama beton. Kekuatan tekan adalah kemampuan beton untuk menerima gaya tekan per satuan luas.

\section{Bahan Penyusun Beton}

Untuk memahami dan mempelajari seluruh perilaku elemen gabungan diperlukan pengetahuan tentang karakteristik masing-masing komponen. Beton dihasilkan dari sekumpulan interaksi mekanis dan kimiawi sejumlah material pembentuknya.

Bahan pembentuk beton terdiri dari campuran agregat halus dan kasar dengan semen dan air sebagai pengikatnya.

\section{Agregat}

Agregat adalah bahan-bahan campuran beton yang saling diikat oleh perekat semen. Agregat ini harus bergradasi sedemikian rupa sehingga seluruh massa beton dapat berfungsi sebagai benda yang utuh, homogen, dan rapat, dimana agregat yang berukuan kecil befungsi sebagai pengisi celah yang ada diantara agregat berukuran besar.

Dua jenis agregat adalah :

a. Agregat kasar ( kerikil, batu pecah)

Agregat kasar adalah agregat dengan besar butir lebih dari $5 \mathrm{~mm}$. ( PBBI

1971, NI-2 ).

Syarat-syarat agregat kasar:

1. Harus terdiri dari butir-butir yang keras dan tidak berpori

2. Butir-butir agregat kasar harus bersifat kekal, artinya tidak pecah atau hancur oleh pengaruh-pengaruh cuaca, seperti terik matahari dan hujan.

3. Agregat kasar tidak boleh mengandung zat-zat yang dapat merusak beton, seperti zat-zat yang reaktif alkali.

4. Agregat kasar tidak boleh mengandung Lumpur lebih dari $1 \%$. Apabila kadar Lumpur melampaui $1 \%$ maka agregat kasar harus dicuci.

b. Agregat halus ( pasir )

Agregat yang berupa pasir sebagai hasil desintegrasi alami dari batu-batuan atau berupa pasir buatan yang dihasilkan oleh alat-alat pemecah batu ( PBBI 1971,N.I.- 2 ).

Syarat agregat halus :

1. Agregat halus terdiri dari butir-butir yang tajam dan keras.

2. Butir agregat halus harus bersifat kekal, artinya tidak pecah atau hancur oleh pengaruh cuaca seperti terik matahari dan hujan.

3. Kandungan lumpur tidak boleh lebih dari 5\% (ditentukan terhadap berat kering). Yang diartikan dengan lumpur adalah bagian-bagian yang dapat melalui ayakan 0,063 mm. Apabila kadar lumpur lebih dari 5\%, maka agregat harus dicuci. 
4. Pasir laut tidak boleh dipakai sebagai agregat halus untuk semua mutu beton, kecuali dengan petunjuk dari lembaga pemeriksaan bahan yang diakui.

\section{Semen}

Semen Portland adalah semen hidrolis yang dihasilkan secara menghaluskan klinker yang terutama terdiri dari silikat-silikat kalsium yang bersifat hidrolis ditambah dengan bahan yang mengatur waktu ikat ( umumnya gips). Semen berfungsi merekatkan butirbutir agregat agar membentuk suatu massa padat dan juga untuk mengisi rongga udara diantara butir agregat. Semen merupakan bahan ikat yang penting dan banyak digunakan dalam pembangunan fisik di sektor konstruksi sipil. Jika semen ditambah air akan menjadi pasta semen. Jika pasta semen ditambah agregat halus akan menjadi mortar dan jika semen ditambah air ditambah agregat halus dan agregat kasar akan menjadi campuran beton segar yang setelah mengeras akan menjadi beton keras ( concrete).

\section{Air}

Air digunakan sebagai bahan pencampur dan pengaduk beton untuk mempermudah pekerjaan. Menurut PBBI 1971 N.I. - 2, pemakaian air untuk beton tersebut sebaiknya memenuhi persyaratan sebagai berikut :

1. Air harus bersih

2. Tidak mengandung lumpur

3. Tidak mengandung garam-garam yang dapat merusak beton seperti asam, zat organik

4. Tidak mengandung minyak dan alkali.

5. Tidak mengandung senyawa asam.

\section{Pengetian Styrofoam}

Styrofoam yang memiliki nama lain polystyrene, begitu banyak digunakan oleh manusia dalam kehidupannya sehari hari. Begitu Styrofoam diciptakan pun langsung marak digunakan di Indonesia. Banyak keunggulan pada styrofoam yang akan sangat menguntungkan bagi para penjual makanan seperti tidak mudah bocor, praktis dan ringan sudah pasti lebih disukai sebagai pembungkus makanan mereka. Bahkan kita tidak dapat dalam satu hari saja tidak menggunakan bahan polimer sintetik.

Polistirena merupakan salah satu polimer yang ditemukan pada sekitar tahun 1930, dibuat melalui proses polimerisasi adisi dengan cara suspensi. Stirena dapat diperoleh dari sumber alam yaitu petroleum. Stirena merupakan cairan yang tidak berwarna menyerupai minyak dengan bau seperti benzena dan memiliki rumus kimia $\mathrm{C}_{6} \mathrm{H}_{5} \mathrm{CH}=\mathrm{CH}_{2}$ atau ditulis sebagai $\mathrm{C}_{8} \mathrm{H}_{8}$.

\section{Faktor Air Semen (FAS)}

Air yang terlalu banyak akan menempati ruang dimana pada waktu beton sudah mengeras dan terjadi penguapan, ruang itu akan menjadi pori. Secara umum diketahui bahwa semakin tinggi nilai FAS, semakin rendah mutu beton. Ada batas-batas dalam hal ini. 
Nilai FAS yang rendah dalam hal ini akan menyebabkan kesulitan dalam pengerjaan, yaitu kesulitan dalam pelaksanaan pemadatan yang pada akhirnya menyebabkan mutu beton menurun.

\section{Metode perawatan beton $\mathrm{K}-300$}

Membuka beton dari cetakan, diletakan pada tempat perawatan (curing area)lalu direndam dalam air selama 28 hari, beton disimpan dalam ruang laboratorium.

\section{Kuat Tekan Beton}

Dalam SK SNI M - 14 -1989 - E dijelaskan pengertian kuat tekan beton yakni besarnya beban per satuan luas yang menyebabkan benda uji beton hancur bila dibebani gaya tekan tertentu, yang dihasilkan oleh mesin tekan. Selanjutnya Mulyono (2006) mengemukakan bahwa kuat tekan beton mengidentifikasikan mutu sebuah struktur di mana semakin tinggi tingkat kekuatan struktur yang dikehendaki, maka semakin tinggi pula mutu beton yang dihasilkan.

Adapun faktor lain yang dapat mempengaruhi mutu kekuatan beton seperti yang dikemukakan oleh Mulyono (2006) yaitu:

1. Proporsi bahan penyusun,

2. Metode pencampuran,

3. Perawatan,

4. Keadaan pada saat pengecoran.

Sifat-sifat dan karaktristik material penyusun beton akan mempengaruhi kinerja beton yang dibuat. Kinerja beton ini harus disesuaikan dengan kelas dan mutu beton yang dikerjakan, sehingga dalam penggunaannya dapat disesuaikan dengan bangunan ataupun konstruksi yang akan dibangun untuk mendapatkan hasil yang memuaskan dan sesuai kebutuhan.

Menurut $P B I^{\prime} 1971$ beton dibagi dalam kelas dan mutu sebagai berikut :

Tabel 1. Kelas dan Mutu Beton

\begin{tabular}{|c|c|c|c|}
\hline $\begin{array}{l}\text { Kelas } \\
\text { Beton }\end{array}$ & $\begin{array}{l}\text { Mutu } \\
\text { Beton }\end{array}$ & $\begin{array}{c}\text { Kekuatan Tekan } \\
\text { Maksimum }\left(\mathrm{Kg} f / \mathrm{cm}^{2}\right)\end{array}$ & Tujuan Pemakaian Beton \\
\hline $\mathrm{I}$ & Bo & $50-80$ & Non-Struktural \\
\hline II & $\begin{array}{c}B 1 \\
K 125 \\
K 175\end{array}$ & $\begin{array}{l}100 \\
125 \\
175\end{array}$ & $\begin{array}{c}\text { Rumah Tinggal } \\
\text { Perumahan } \\
\text { Perumahan }\end{array}$ \\
\hline III & $\begin{array}{l}K 225 \\
>K 225\end{array}$ & $\begin{array}{c}225 \\
>225\end{array}$ & $\begin{array}{c}\text { Jembatan, Bangunan } \\
\text { tinggi, Terowongan } \\
\text { kereta api }\end{array}$ \\
\hline
\end{tabular}

Beton merupakan material struktur yang umum digunakan karena penggunaannya yang sangat luas dalam bidang kontruksi bangunan sipil. Sebagian besar bangunan komponen utamanya terbuat dari beton. Ada berbagai jenis beton yang biasanya digunakan dalam konstruksi antara lain beton normal, beton mutu tinggi. 
Biasanya dipercayai bahwa beton mengering setelah pencampuran dan peletakan, Sebenarnya beton tidak menjadi padat karena air menguap tetapi semen berhidrasi mengelem komponen lainnya bersama dan akhirnya membentuk material seperti batu, Beton digunakan untuk membuat perkerasan jalan, struktur bangunan, pondasi, jalan, jembatan penyeberangan, struktur parkiran, dasar untuk pagar/gerbang, dan semen dalam bata atau tembok, dalam hal ini penelitian ini menggunakan campuran Styrofoam terhadap penambahan campuran beton.

Pada penelitian ini styrofoam digunakan dalam campuran beton, dari penelitian ini diperkirakan beton memiliki kuat tekan yang lemah sehingga dalam penelitian ini menggunakan mutu beton k-300.

Dengan campuran variasi penggunaan styrofoam ini diharapkan bisa bermanfaat untuk bidang konstruksi sebagai alternatif untuk menghambat laju pesawat ketika mengalami tergelincir dari landasan pacu sebagai pengaman ujung landasan runway.

\section{METODE PENELITIAN}

Metode yang diterapkan dalam penelitian ini adalah metode eksperimen, yaitu penelitian yang bertujuan untuk menyelidiki hubungan satu sama lain dan membandingkan hasilnya. Pengujian yang dilakukan dalam penelitian ini meliputi pengujian bahan, pengujian kuat tekan . Pengujian dilakukan menggunakan standart SKSNI.

Berdasarkan rumusan masalah di atas dan mengingat luasnya cakupan penelitian beton, maka perlu adanya pembatasan masalah agar tujuan yang diinginkan dapat tercapai, Adapun batasan masalah tersebut adalah sebagai berikut:

1. Bahan additif yang digunakan pada campuran beton adalah butiran styrofoam dengan variasi persentase $0 \%, 10 \%, 15 \%, 20 \%$.

2. Benda uji untuk pengujian kuat tekan beton dibuat dalam bentuk kubus dengan ukuran $15 \mathrm{~cm}$ x $15 \mathrm{~cm}$ x $15 \mathrm{~cm}$.

3. Campuran beton menggunakan campuran beton mutu k-300 yang digabung dengan styrofoam dengan komposisi campuran (semen : pasir : batu pecah, air, dan styrofoam)

4. Perawatan beton dilakukan dengan merendam beton dalam bak air.

5. Pengujian dilakukan pada umur 28 hari.

\section{Bahan dan Alat Penelitian}

Bahan yang digunakan dalam penelitian ini antara lain :

a. Air, yang digunakan dalam penelitian ini adalah air Laboratorium Dinas PU Bina Marga Provinsi Sumatera Selatan.

b. Semen yang digunakan adalah Semen batu raja atau Tipe I ukuran $50 \mathrm{~kg}$.

c. Agregat

Agregat halus : Agregat halus berupa Pasir tanjung raja

Agregat kasar : Agregat kasar dipakai batu pecah yang berasal dari Lahat.

d. Styrofoam, yang digunakan dengan variasi persentasi 0\%. 10\%. 15\%. 20\% Terhadap volume yang digunakan dalam campuran beton. 


\section{PEMBAHASAN}

\section{Pengelolahan Data Hasil Uji Kuat Tekan Beton}

Setelah data hasil uji kuat tekan beton diperoleh, data tersebut di olah dengan menggunakan rumus-rumus sumber Sebagai berikut :

$$
\begin{aligned}
& \quad \sum b i=\frac{W}{A} \\
& \mathrm{~S} \sqrt{\sum_{i=1}^{N} \frac{(\sigma b i-\sigma b m)^{2}}{N-1}} \\
& \sigma \mathrm{bm}=\sum_{i=1}^{n} \frac{\sigma b i}{N} \\
& \sigma \mathrm{bk}=\sigma \mathrm{bm}-1,64 \\
& \text { Ket : } \\
& \sigma \text { bi }=\text { Kuat tekan beton masing-masing sample }\left(\mathrm{kg} / \mathrm{cm}^{2}\right) \\
& \sigma \mathrm{bm}=\text { Kuat tekan beton rata-rata }\left(\mathrm{kg} / \mathrm{cm}^{2}\right) \\
& \sigma \text { bk }=\text { Kuat tekan beton karekteristik }\left(\mathrm{kg} / \mathrm{cm}^{2}\right) \\
& \mathrm{W}=\text { Berat beban masing0masing sample }(\mathrm{kg}) \\
& \mathrm{A}=\text { Luas penampang kubus sample }\left(\mathrm{cm}^{2}\right) \\
& \mathrm{S}=\text { Deviasi standar } \\
& \mathrm{N}=\text { Jumlah seluruh sample } \\
& 1,64=\text { konstanta }
\end{aligned}
$$

\begin{tabular}{|c|c|c|c|c|c|}
\hline \multirow[b]{2}{*}{ Kondisi Beton } & \multicolumn{4}{|c|}{$\nabla_{2}$ Persentase Penambahan Styrofoam } & \multirow[b]{2}{*}{$\sigma b k$} \\
\hline & $\begin{array}{l}\text { Beton } \\
\text { Normal }\end{array}$ & $\begin{array}{c}\text { styrofoam } \\
10 \%\end{array}$ & $\begin{array}{c}\text { styrofoam } \\
15 \%\end{array}$ & $\begin{array}{c}\text { styrofoam } \\
20 \%\end{array}$ & \\
\hline Karakteristik (K) Beton & 317.39 & 258.96 & 222.49 & 140.58 & $\mathrm{Kg} / \mathrm{cm}^{2}$ \\
\hline
\end{tabular}

Nilai deviasi menunjukkan tingkat keberasilan pelaksanaan lapangan. Semakin kecil deviasi yang diperoleh, maka semakin tinggi tingkat keberasilan pelaksanaan penelitian.

Tabel 2. Hasil Rekapitulasi Penurunan Kuat tekan Beton

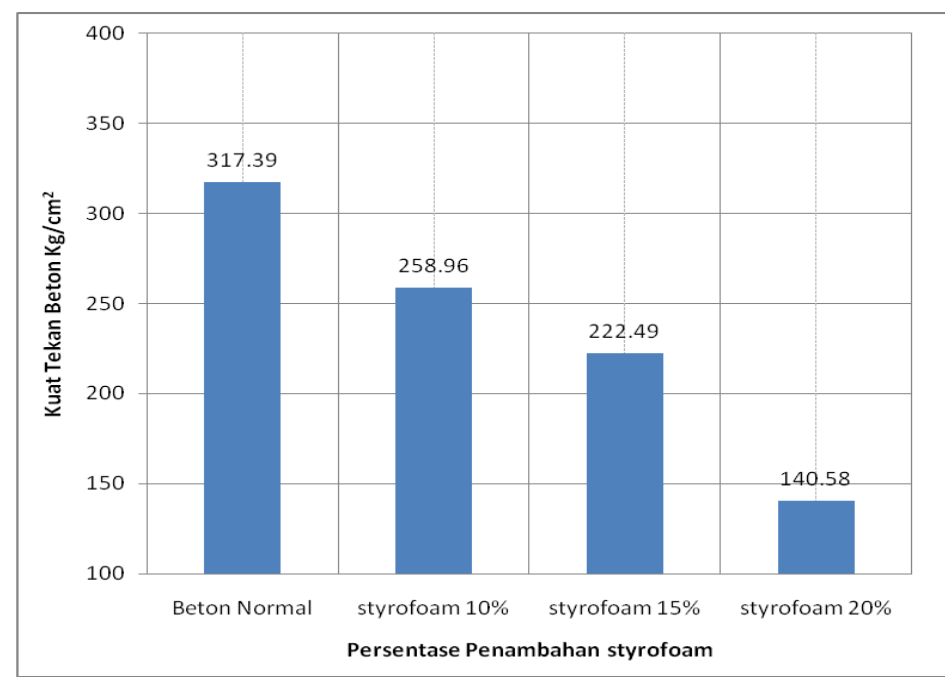

Gambar 1. Hasil perbandingan Prosentase Penambahan Styrofoam terhadap kuat tekan beton 
Dari hasil pengujian kuat tekan beton setelah berumur 28 hari diperoleh kuat tekan beton untuk beton normal sebesar $317,39 \mathrm{~kg} / \mathrm{cm}^{2}$, pada beton dengan penambahan Styrofoam $10 \%$ terjadi penurunan sebesar $258,96 \mathrm{~kg} / \mathrm{cm}^{2}$ dan penambahan Styrofoam $15 \%$ terjadi penurunan sebesar $222,49 \mathrm{~kg} / \mathrm{cm}^{2}$ dan pada penambahan Styrofoam $20 \%$ mengalami penurunan yang cukup siknifikan sebanyak $140,58 \mathrm{~kg} / \mathrm{cm}^{2}$. Maka disimpulkan bahwa beton yang dicampur Styrofoam dapat mengurangi kuat tekan beton, dan beton tersebut menjadi rapuh.

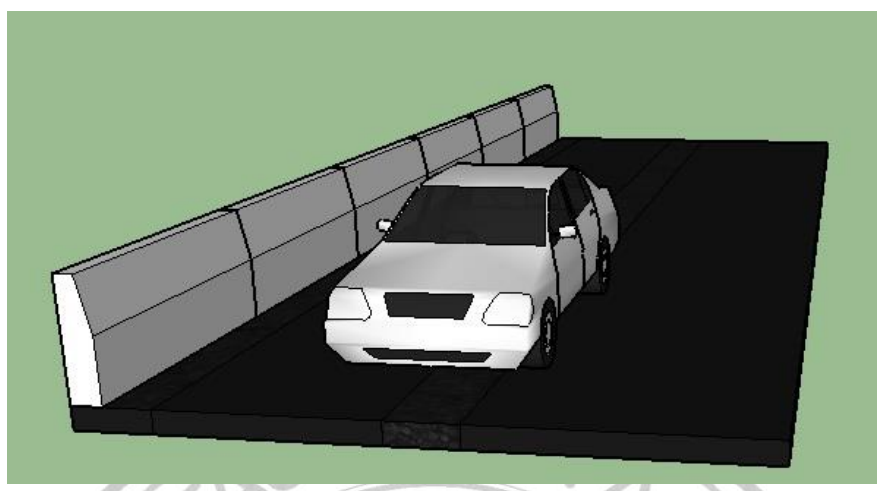

Gambar 2. Desain Marka Ganti Ulang

Sehingga dapat dianalogikan bahwa marka beton yang terbuat dari beton dengan additive Styrofoam cukup kuat untuk menahan bebannya sendiri dan pengaruh lingkungan. Namun cukup rapuh jika terkena benturan kendaraan yang secara otomatis mampu meredam benturan dan meminimalisir kerusakan kendaraan.

\section{KESIMPULAN}

Dari hasil penelitian ini dapat ditarik berapa kesimpulan sebagai berikut:

1. Penambahan Styrofoam kedalam adukan beton dapat menurunkan kuat tekan beton normal sebesar $317,39 \mathrm{~kg} / \mathrm{cm} 2$, penambahan Styrofoam $10 \%$ terjadi penurunan sebesar 258,96 kg/cm2, dan penambahan Styrofoam $15 \%$ terjadi penurunan sebesar $222,49 \mathrm{~kg} / \mathrm{cm} 2$, dan pada penambahan Styrofoam pada $20 \%$ mengalami penurunan yang cukup siknifikan sebanyak 140,58 kg/cm2,

2. Beton dengan additive Styrofoam cukup kuat untuk menahan bebannya sendiri dan pengaruh lingkungan

3. Beton cukup rapuh jika terkena benturan kendaraan yang secara otomatis mampu meredam benturan dan meminimalisir kerusakan kendaraan.

\section{SARAN}

1. Perlu dilakukan penelitian lanjutan sehubungan denga beban benturan kendaraan yang sangat tergantung dari bobot dan kecepatan kendaraan yang membentur marka jalan.

2. Dalam penelitian selanjutnya butuh ketelitian dalam melaksanakan penelitian dilaboratorium terutama dalam penentuan bahan campuran atau material, penambahan Styrofoam maupun bahan adiktif lainya. 
3. Perlu desain lanjutan yang berhubungan dengan bentuk marka beton yang sesuai dengan kebutuhan dan mudah untuk diganti ulang

4. Kemudian untuk para pembaca khususnya bagi dosen jurusan teknik sipil yang akan menyusun penelitian, sekiranya dapat melanjutkan penelitian ini dengan penambahan Styrofoam dengan persentase yang lebih berpariasi.

\section{DAFTAR PUSTAKA}

Departemen Pekerjaan Umum dan Tenaga Listrik.1971. "Peraturan Beton Bertulang Indonesia”.LPMB. Bandung

Departemen Pekerjaan Umum dan Tenaga Listrik.1976. "Manual Pemeriksaan Bahan Jalan".LPMB. Bandung

Departemen Pekerjaan Umum dan Tenaga Listrik.1991. "Tata Cara Pembuatan Rencana Campuran Beton Normal'.LPMB. Bandung

http://id.wikipedia.org/wiki/Beton. (19 maret 2012)

http://eprints.undip.ac.id/34703/5/1704_CHAPTER_II.pdf (14 maret 2012)

http://www.ilmusipil.com/pengertian-beton-adalah. (14 maret 2012)

http://mualim.wordpress.com/2007/07/23/teknik-pembuatan-beton-1/. (14 maret 2012)

http://www.ftsl.itb.ac.id/wp-content/uploads/2009/10/2.-Irma-Aswani-A.-dkk-Vol.16No.2.pdf (19 maret 2012)

Mulyono, Tri.2003. "Teknologi Beton".Penerbit Andi.Jakarta

V, Sunggono KH.Ir. ”Buku Teknik Sipil’.'Bandung: Nova. 